\title{
The association of TB with HIV infection in Oromia Regional National State, Ethiopia in 2006/7
}

\author{
Abera Bekele $^{1,2}$, Kate Fleming ${ }^{1}$, Zelalem Habtamu², Andrew Fogarty ${ }^{1}$
}

\begin{abstract}
Background: Infection with Human Immunodeficiency Virus (HIV) is an established risk factor for tuberculosis infection. Population-based data on associations between HIV and tuberculosis (TB) can provide an epidemiological assessment of the impact of HIV infection on TB in environments where individual based data are difficult to collect.

Method: We used an ecological study to assess the association between infection with HIV and tuberculosis in Oromia Region National State, Ethiopia in 2006/7.

Result: The prevalence of HIV infection was significantly associated with the incidence of TB across the areas in Oromia region $(r=0.69, \mathrm{p}<0.01)$. Similar associations were also seen for the prevalence of HIV infection with the incidence of smear positive tuberculosis, smear negative tuberculosis and extra-pulmonary tuberculosis.

Conclusion: Ecological association between HIV and TB is strong in Oromia Regional state. Therefore, in areas where there are high TB case notification rates, it is important to consider the possibility that the prevalence of HIV may also be increasing, and take appropriate public health measures to assess and address these issues. [Ethiop.J.Health Dev. 2009;23(1):63-67]
\end{abstract}

\section{Introduction}

Infection with Human Immunodeficiency Virus (HIV) is an established risk factor $(1,2)$ for acquiring and developing infection with tuberculosis, and the recent increase in the worldwide prevalence of HIV infection has contributed to the rising global incidence of TB. Infection with $\mathrm{TB}$ is a particular problem in Ethiopia with an estimated annual incidence of 168 cases per 100,000 population for smear positive tuberculosis and 378 cases per 100,000 population for all forms of TB (3). Infection with HIV is also an emerging problem in Ethiopia, and according to the Federal HIV/AIDS Prevention and Control Office, the single point HIV prevalence in 2007 was estimated to be $7.7 \%$ in urban areas (with a total number of 518,383 cases) and $0.9 \%$ in rural areas (with a total of 320,629 cases) (4). A recent review of tuberculosis in Ethiopia noted that 'existing information on the association between HIV and TB in Ethiopia is limited' (5). Although hospital-based cross sectional studies in Ethiopia have reported that most of tuberculosis patients were co-infected with $\operatorname{HIV}(6,7)$, with recent estimates ranging from $46 \%$ (8) to $65 \%$ (9) no analyses have assessed the association between infection with both HIV and tuberculosis in Ethiopia at a regional level, to provide data on how these two infections are interrelated in a population-based analysis. We have used public health data to test the hypothesis that the prevalence of infection with HIV and TB are correlated in Oromia Regional National State in Ethiopia using an ecological study design.

\section{Methods}

\section{Study population}

Oromia Region is the largest of the nine regions in Ethiopia and in 2008 had a population of about 28.8 million individuals, of whom approximately $85 \%$ live in rural areas. This state is administratively divided into 17 zones and 5 towns. Health facilities report all TB cases that are detected at their TB clinics and each patient is given a unique district number that is entered into the district TB registers. These data are checked for completeness and accuracy and reported to the National TB and Leprosy Control Programme. The case notification report format includes information for reporting the site, dates, age category, sex and type of tuberculosis (new smear-positive, smear-negative, extrapulmonary TB). In this study the data for TB case notification were obtained from the Oromia Regional Health Bureau for all TB patients who were registered between the periods of 1 September 2006 to 31 August 2007.

Data for the regional HIV prevalence were obtained from Oromia Regional Health Bureau. These data were collected in 2007 by a campaign that targeted social mobilization and the expansion of the antiretroviral service coverage across the region, using all available means including community leaders, religious leaders, school teachers and all government organizations. Blood samples were collected from all volunteers at health facilities, working places and in the community by trained health workers. The sample was tested for HIV immediately using a rapid test kit. Results were compiled at the district level and reported to the zonal health department and regional health bureau in a similar way to that used to report the TB data. Data were not available on the prevalence of HIV infection in Nekemte town which was thus omitted from any analyses.

${ }^{1}$ University of Nottingham, Division of Epidemiology and Public Health, Nottingham, United Kingdom; ${ }^{2}$ Oromia Regional National State Health Bureau, Shashemene, P.O.Box 138, Ethiopia, Email address, Abera_bekele@ yahoo.com, Addis Ababa 


\section{Statistical analysis}

The data were analyzed using SPSS for Windows version 14. The incidence of different forms of TB was calculated by dividing the detected cases of each form of TB by the total number of population and presented per 1000 population. The ecological association between different types of tuberculosis and prevalence of HIV across the zones and towns was estimated using the Spearman's Correlation Test with a p-value of 0.05 considered to represent statistical significance.

\section{Results}

A total of 40779 cases of TB including 12818 smear positive pulmonary TB cases were reported in 2006/2007 by health facilities in Oromia Region. The incidence of TB was higher in urban areas (5.6 cases per 1000 population) compared to rural areas (1.3 per 1000).

A total of 29,590 individuals living in Oromia Region were reported to be seropositive for HIV infection in 2006/2007. Similar to tuberculosis, HIV infection had a higher reported prevalence in urban areas (1.5\%) compared to rural areas $(0.1 \%)$.

In the ecological analysis, there was a positive and strong ecological association $(\mathrm{r}=0.69 \mathrm{p}=0.01)$ between the prevalence of HIV infection and the incidence of all forms of TB (Table 2, Figure 1,). This association was also seen for smear positive pulmonary TB $(\mathrm{r}=0.51$, $\mathrm{p}=0.02)$, smear negative pulmonary TB $(\mathrm{r}=0.70, \mathrm{p}<0.01)$ and extra pulmonary TB $(\mathrm{r}=0.64, \mathrm{p}<0.01)$.

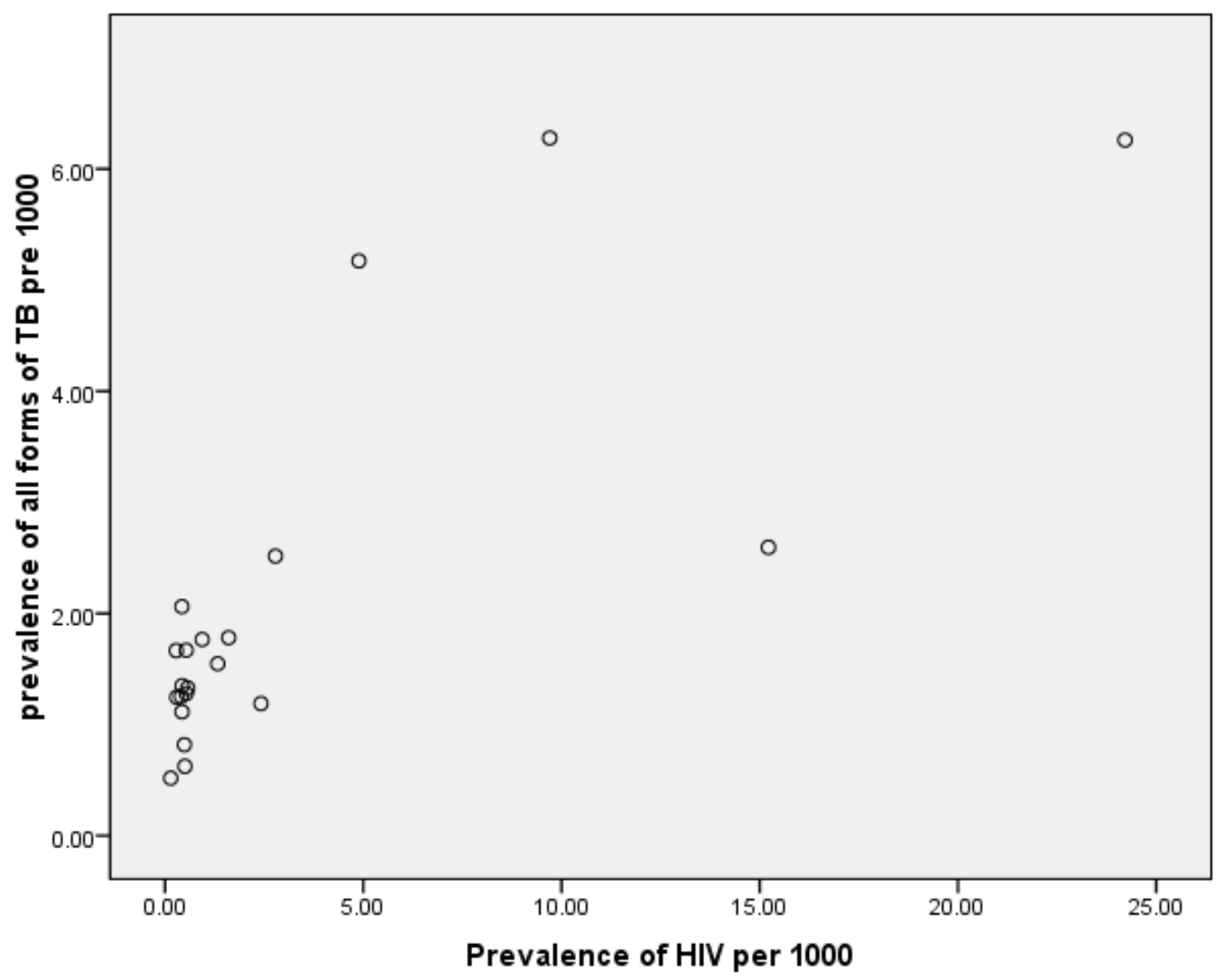

Figure 1: An ecological analysis of the association between the incidence of all forms of tuberculosis infection and the prevalence of HIV infection in Oromia Region in 2006/2007 
Table 1: The distribution of different forms of TB and prevalence of HIV infection by area of resident in Oromia Region, Ethiopia, 2006/2007

\begin{tabular}{|c|c|c|c|c|c|c|c|c|c|c|c|c|c|c|}
\hline & \multirow[t]{2}{*}{ Zone or town } & \multirow[t]{2}{*}{ Population } & \multicolumn{2}{|c|}{ Smear Positive } & \multicolumn{2}{|c|}{ Smear Negative } & \multicolumn{2}{|l|}{ EPTB } & \multicolumn{2}{|c|}{$\begin{array}{l}\text { Retreatment } \\
\text { cases }\end{array}$} & \multicolumn{2}{|c|}{ All forms } & \multicolumn{2}{|c|}{ HIV positive } \\
\hline & & & $\mathbf{N}$ & $\begin{array}{l}\text { Casel } \\
1000 \\
\end{array}$ & $\mathbf{N}$ & $\begin{array}{l}\text { Casel } \\
1000 \\
\end{array}$ & $\mathbf{N}$ & $\begin{array}{l}\text { Casel } \\
1000 \\
\end{array}$ & $\mathbf{N}$ & $\begin{array}{l}\text { Casel } \\
1000 \\
\end{array}$ & $\mathbf{N}$ & $\begin{array}{l}\text { Casel } \\
1000 \\
\end{array}$ & $\mathbf{N}$ & $\begin{array}{l}\text { Casel } \\
100 \\
\end{array}$ \\
\hline \multicolumn{15}{|l|}{ Towns } \\
\hline & $\begin{array}{l}\text { Adama twn } \\
\text { Asela town }\end{array}$ & 224435 & 319 & 1.4 & 595 & 2.7 & 436 & 1.9 & 55 & $\begin{array}{l}0.245 \\
0.012\end{array}$ & 1,405 & 6.3 & 5,435 & 2.42 \\
\hline & & 77069 & 60 & 0.8 & 87 & 1.1 & 52 & 0.7 & 1 & 9 & 200 & 2.6 & 1,173 & 1.52 \\
\hline & Shashemene & 102270 & 211 & 2.1 & 163 & 1.6 & 125 & 1.2 & 30 & 0.293 & 529 & 5.2 & 500 & 0.49 \\
\hline & Nekemte & 82972 & 357 & 4.3 & 533 & 6.4 & 573 & 6.9 & 9 & 0.108 & 1,472 & 18 & - & - \\
\hline & Jimma town & 162300 & 254 & 0.1 & 284 & 0.1 & 473 & 0.2 & 8 & 0.049 & 1,019 & 0.5 & 1,575 & 0.97 \\
\hline Total & Town & 649046 & 1,201 & 1.9 & 1,662 & 2.6 & 1,659 & 2.6 & 103 & 0.159 & 4,625 & 7.1 & 8,683 & 1.34 \\
\hline \multicolumn{15}{|c|}{ Zones } \\
\hline & N. Shoa & 1637011 & 648 & 0.4 & 1,106 & 0.7 & 364 & 0.2 & 57 & 0.034 & 2,175 & 1.3 & 932 & 0.06 \\
\hline & E. Shoa & 1384885 & 889 & 0.6 & 1,197 & 0.9 & 1,343 & 1.0 & 56 & 0.040 & 3,485 & 2.5 & 3,854 & 0.28 \\
\hline & S. W.Shoa & 1234718 & 738 & 0.6 & 574 & 0.5 & 839 & 0.7 & 49 & 0.040 & 2,200 & 1.8 & 1,979 & 0.16 \\
\hline & W. Shoa & 2263747 & 978 & 0.4 & 786 & 0.3 & 1,673 & 0.7 & 65 & 0.029 & 3,502 & 1.5 & 3,003 & 0.13 \\
\hline & Arsi & 2676553 & 1,382 & 0.5 & 1,083 & 0.4 & 1,093 & 0.4 & 56 & 0.021 & 3,614 & 1.4 & 1,154 & 0.04 \\
\hline & W. Arsi & 1736361 & 913 & 0.5 & 695 & .4 & 521 & 0.3 & 45 & 0.026 & 2,174 & 1.3 & 698 & 0.04 \\
\hline & E. Wolega & 1110623 & 328 & 0.3 & 543 & 0.5 & 445 & 0.4 & 4 & 0.004 & 1,320 & 1.2 & 2,686 & 0.24 \\
\hline & H. Gudru W. & 657232 & 96 & 0.1 & 130 & 0.2 & 180 & 0.3 & 4 & 0.006 & 410 & 0.6 & 328 & 0.05 \\
\hline & W. Welega & 1436387 & 805 & 0.6 & 680 & 0.5 & 875 & 0.6 & 37 & 0.026 & 2,397 & 1.7 & 766 & 0.05 \\
\hline & Kelem Wel. & 867887 & 355 & 0.4 & 672 & 0.8 & 741 & 0.9 & 21 & 0.024 & 1,789 & 2.1 & 368 & 0.04 \\
\hline & Bale, Zonal & 1436479 & 593 & 0.4 & 609 & 0.4 & 612 & 0.4 & 24 & 0.017 & 1,838 & 1.3 & 765 & 0.05 \\
\hline & Jima & 2824100 & 419 & 1.6 & 345 & 1.7 & 688 & 2.9 & 9 & 0.003 & 1,461 & 6.3 & 400 & 0.01 \\
\hline & Borena & 1190071 & 630 & 0.5 & 420 & 0.4 & 236 & 0.2 & 40 & 0.034 & 1,326 & 1.1 & 508 & 0.04 \\
\hline & Guji & 1343584 & 928 & 6.9 & 474 & 0.4 & 752 & 0.6 & 84 & 0.063 & 2,238 & 1.7 & 377 & 0.03 \\
\hline & E.Harerge & 2999695 & 1,216 & 0.4 & 1,477 & 0.5 & 1,024 & 0.3 & 20 & 0.007 & 3,737 & 1.2 & 887 & 0.03 \\
\hline & W.Harerge & 2000837 & 562 & 0.3 & 721 & 0.4 & 316 & 0.2 & 38 & 0.019 & 1,637 & 0.8 & 972 & 0.05 \\
\hline & Illubabor & 1316107 & 494 & 0.4 & 710 & 0.5 & 1,087 & 0.8 & 32 & 0.024 & 2,323 & 1.8 & 1,230 & 0.09 \\
\hline Total & Zones & 28116277 & 11,974 & 0.4 & 12,222 & 0.4 & 12,789 & 0.5 & 641 & 0.023 & 37,626 & 1.3 & 20,923 & 0.07 \\
\hline & Oromia & 28765323 & 13,175 & 0.5 & 13,884 & 0.5 & 14,448 & 0.5 & 744 & 0.026 & 42,251 & 1.5 & 29,606 & 0.10 \\
\hline
\end{tabular}


Table 2: An ecological analysis of the association between the incidence of tuberculosis infection and the prevalence of HIV infection in Oromia Region in 2006/2007

\begin{tabular}{lll}
\hline & correlation coefficient & p value \\
\hline All forms of TB & 0.69 & $<0.01$ \\
Stratified analysis of subgroups of & & \\
$\frac{\text { TB }}{\text { Smear positive Pulmonary TB }}$ & 0.51 & 0.02 \\
Smear negative pulmonary TB & 0.70 & $<0.01$ \\
Extra-pulmonary TB & 0.64 & $<0.01$ \\
\hline
\end{tabular}

* using Spearman's correlation coefficient

TB $=$ tuberculosis

\section{Discussion}

In this ecological analysis, we have demonstrated a positive association between the incidence of TB and prevalence of HIV infection using a 2006/7 data from Oromia Region Health Bureau, suggesting that the prevalence of HIV infection is associated with up to $47 \%$ of the variance in tuberculosis infection at the regional level. To our knowledge, this is the first report that HIV infection is associated with infection of tuberculosis in this region using population-based data.

The strengths of our data are that they were collected as part of the routine public health monitoring for tuberculosis infection and as part of an unrelated campaign to estimate the prevalence of HIV infection. We acknowledge that an ecological study design demonstrates correlations between factors at a population-based level, but does not permit conclusions to be drawn regarding the causal relations between the exposures/outcomes of interest. Moreover, the methods used to collect the data on the burden of infection with TB and HIV are potentially flawed and susceptible to potential biases and confounding factors including differentials in reporting symptoms, access to health care and diagnostic facilities (10), and cultural attitudes to tuberculosis and HIV infection. For example, the data on TB incidence would have been collected from individuals who appeared for treatment, while the data on HIV prevalence were from volunteers, each adding different biases to the total study population. In addition, the use of data from smear-negative TB cases must be regarded with caution as this diagnostic category may include a variety of false-positive diagnoses. However, despite these limitations we were still able to observe ecological associations between the incidence of tuberculosis infection and prevalence of HIV infection. This suggests that the well recognised association between these two diseases at the individual level is now manifesting itself at a population-based level in Ethiopia. If causal, the size of the association suggests that a sizable proportion of the burden of infection with TB in this region of Ethiopia may be a consequence of HIV infection.

Although existing information on the association between HIV and TB infection in Ethiopia is limited (5), our findings are consistent with a series of health-facility based studies which have reported an association between HIV infection and TB from Ethiopia. A hospital based study in Ethiopia once (7) demonstrated the rising incidence of both TB and HIV infection in Addis Ababa. Similarly, a second cross-sectional hospital-based study by Kassu et al from North-West Ethiopia again showed the presence of the HIV in 52\% of TB patients' blood (6), while a prospective study from Southern Ethiopia suggests HIV co-infection among patients with TB infection was approximately $18-21 \%$ (11). A recent review of the development of the HIV epidemic in Ethiopia suggested that while there are signs of a possible decrease in prevalence in urban areas, the prevalence of HIV infection is increasing in rural areas. Having this in mind, the quality of the data available still makes all observations tentative at this stage (12).

In summary, one can see an ecological association between HIV and TB suggesting that these two threatening infectious diseases are associated in Oromia Region at the population level. This may have implications for both prevention and case management of these infections in Ethiopia. In particular it suggests that there may be a case for strengthening the antituberculosis and anti-retroviral programmes using all available resources (13). In areas where there are high TB case notification rates, it is important to consider the possibility that prevalence of HIV may also be increasing in these areas. Thus, this fact is a peak point to take appropriate public health measures to assess and address the problem.

\section{References}

1. Corbett E, Catherine J, Walker N, Maher D, Williams B, Raviglione $\mathrm{M}$, et al, The Growing Burden of Tuberculosis. Global Trends and Interactions with the HIV Epidemic. Arch Intern Med, 2003;163:1009-1021.

2. Dye C, Scheele S, Dolin P, Pathania V, Ravi- glione MC. Global Burden of Tuberculosis: Estimated Incidence, Prevalence, and Mortality by Country. JAMA, 1999;282(7): 677-686. 
3. WHO, Global Tuberculosis Database. http://www.who.int/globalatlas/dataQuery/default.as p.

4. FMoH . Single point HIV prevalence estimate. National consensus Meeting on Single point HIV prevalence estimate, Adama, Ethiopia 11-12 May, 22007.

5. Demissie M, Omer OA, Lindjorn B, Hombergh J. Tuberclosis In: Berhane Y, Hailemariam D and Kloos (Eds): The Epidemiology and Ecology of Health and Disease in Ethiopia. Shama Books, Addis Ababa, Ethiopia. 2006;409-434.

6. Kassu A, Mengistu G, Ayele B, Diro E, Mekonnen F, Ketema D et al. Coinfection and clinical manifestations of tuberculosis in human immunodeficiency virus- infected and -uninfected adults at a teaching hospital, northwest Ethiopia. 2007;40(2):116-122.

7. Adaraye G, Bruchfeld J, and Assefa G, The Relationship between disease pattern and disease burden by chest radiography,M.tuberculosis load and HIV status in patients with pulmonary tuberculosis in Addis Ababa. Infection, 2004;32:333-338.

8. Van den Homberge J, Atnafu A, van eutokom H. Chest X-ray and the diagnosis of PTB in an urban area with a high prevalence of HIV/TB co-infection. Abstract Annual Medical Association Conference, May 22-24, Addis Ababa, Ethiopia.
9. Bruchfeld J, Aderaye G, Palme IB et al. Molecular Epidemiology and Drug Resistance of Mycobacterium tuberculosis isolates from Ethiopian Pulmonary Tuberculosis Patients with and without Human Immunodeficiency Virus Infection. Journal of Clinical Microbiology 2002;5(40):1636-1643.

10. Cambanis A, Yassin M, Ramsay A, Squire S, Arbide I and Cuevas L. Rural poverty and delayed presentation to tuberculosis services in Ethiopia. Tropical Medicine and International Health, 2005; 10(4):330-335.

11. Yasin M, Takele L, Gebresenbet S, Girma E, Lera M , Lendebo E, Cuevas L. HIV and Tuberculosis Coinfection in the Southern Region of Ethiopia: A Prospective Epidemiological Study. Scand J Infect Dis, 2004;36:670-673.

12. Hladik W, Shabbir I, Jelaludin A, Woldu A, Tsehaynesh $M$ and Tadesse. W HIV/AIDS in Ethiopia: where is the epidemic heading? Sex. Transm. Inf., 2006. 82.

13. Jerene D, Næss A and Lindtjørn B. Antiretroviral therapy at a district hospital in Ethiopia prevents death and tuberculosis in a cohort of HIV patients AIDS Research and Therapy 2006;10. 